\title{
Designerly Research Methods and Researcherly Design Methods
}

\section{Ricardo Sosa}

Auckland University of Technology

This paper builds on the complementary identities distinguished by Joyce Yee of a 'researcherly designer' as a designer trained in research and a 'designerly researcher' as its counterpart: a researcher trained in design (Yee, 2017). Joyce reflects that adopting these two roles informs her practice allowing her to select "the right research tools for different purposes". Here, I extend and examine this duality paying close attention to the methods used in these two professional practices. I argue that 'the same' techniques, tools, and methods are used by individuals when they engage in design activity and when they 'change hats' to engage in research activity. Whilst it is certainly true that individuals integrate and blend these activities within the same project, I make the argument that how they use these methods can be clearly distinguished by the purposes for which they use them. Individuals who are in the position to execute roles as different as designers and researchers are 'ambidextrous' and they cultivate creative synergies between these worlds. However, switching membership between such different communities is not without its challenges (Gold, 2007). The paper addresses the opportunities, risks, and ethical tensions that come from 'changing hats' and it draws from earlier work on the creative adaptation of design methods for cross- disciplinary research (Sosa \& Grocott, 2020). The paper concludes with recommendations and generative questions for those who embark on the advanced practices of design and research.

\section{KEYWORDS}

Research methodologies, Professional identity,

Communities of practice, Epistemologies, Research ethics

Gold, R. (2007). The plenitude: Creativity, innovation, and making stuff: Mit Press.

Sosa, R., \& Grocott, L. (2020). The creative translation of design methods into social research contexts. In H. Kara \& S. Khoo (Eds.), Researching in the Age of COVID-19 Vol 3: Volume III: Creativity and Ethics

(Vol. 3, pp. 9-19). Bristol, UK: Policy Press.

Yee, J. (2017). The researcherly designer/the designerly researcher. In L Vaughan ( $E d)$

Practice-based Design Research (pp. 155). London: Bloomsbury Academic. 